\title{
HUBUNGAN TINGKAT KEDISIPLINAN SISWA \\ DENGAN PRESTASI BELAJAR PADA MATA PELAJARAN PKn \\ KELAS VIII DI SMP NEGERI SATU ATAP 1 CIPAKU
}

\author{
Dudang Suryanto', Endang ${ }^{2}$ \\ 1,2STKIP Subang \\ 1'dudangsuryanto1@gmail.com, ${ }^{2}$ endang@yahoo.com
}

\begin{abstract}
Method of Discussion and Instructional Media has a very big role in shaping an entire process This is nothing else because through the Method of Discussion and Instructional Media can gain knowledge and through knowledge also humans will be able to do good. The main problem in this study is the extent to which the Effects of Discussion Methods and Instructional Media on Student Achievement in PKN Subjects in Class X of SMA Muhammadiyah Pangandaran. While the method that the author uses in this study is the field research method (field research) in order to find out students' reading interest which is supported by library research methods in order to have a strong theoretical foundation. Therefore, the data collection tools used were in the form of questionnaires, observation sheets and interview guide sheets. The results showed that there was no relationship between variable $X$ (Student Learning Discipline) and Y Variables (Civics Learning Outcomes).
\end{abstract}

Keywords: Educative, Discussion, Interview

\begin{abstract}
ABSTRAK
Metode Diskusi dan Media Instruksional Edukatif memiliki peranan yang sangat besar dalam membentuk suatu seluruh proses Hal ini tidak lain karena melalui Metode Diskusi dan Media Instruksional Edukatif dapat memperoleh pengetahuan dan melalui pengetahuan pula manusia akan mampu untuk berbuat kebaikan. Masalah pokok dalam penelitian ini adalah sejauh mana Pengaruh Metode Diskusi dan Media Instruksional Edukatif Terhadap Prestasi siswa Pada Mata Pelajaran PKN di Kelas X SMA Muhammadiyah Pangandaran. Sedangkan metode yang penulis gunakan dalam penelitian ini adalah metode penelitian lapangan (field research) dalam rangka mengetahui minat baca siswa yang ditopang dengan metode penelitian pustaka (library research) agar memiliki landasan teoretis yang kuat. Karenanya, alat pengumpulan data yang digunakan berupa angket, lembar observasi dan lembar pedoman wawancara. Hasil penelitian menunjukan bahwa tidak ada hubungan antara variable $X$ (Disiplin Belajar Siswa) dengan Variabel Y (Hasil belajar PKn).
\end{abstract}

Kunci : Edukatif, Diskusi, Wawancara 


\section{A. Pendahuluan}

Pendidikan Kewarganegaraan adalah pendidikan yang bersumber kepada ajaran mulia, oleh sebab itu penanaman pengetahuan bukanlah menjadi sasaran akhir, akan tetapi sebagai tujuan akhir adalah kemampuan menghayati dan mengamalkan Pancasila.

Adapun usaha-usaha dalam bidang pendidikan yang dilandasi pancasila oleh pancasila dan UUD 1945 yaitu terdapat dalam pembukaan UUD 1945 alinea, 4, mengatakan bahwa:Penyusun kemerdakaan kebangsaan yang berdasarkan kepada; Ketuhanan Yang Maha Esa, Kemanusiaan yang adil dan beradab, persatuan Indonesia, Sekolah sebagai lembaga pendidikan formal yang mana merupakan peningkatan dan kesinambungan dari pendidikan keluarga. Semua unsur dalam pendidikan formal itu, baik gurunya maupun anak didiknya hendaknya tindak tanduk mencerminkan nilainilai luhur Pancasila dan benar benar menghayati dan mengamalkan Pancasila. Mengapa Pendidikan Kewarganegaraan menduduki tempat yang vital, sentral dan strategis di dalam pendidikan nasional ? karena Pendidikan Kewarganegaraan itu merupakan pendidikan yang sifatnya mendasar, dan tanpa adanya Pendidikan Kewarganegaraan maka segala keterampilan atau akal ketinggian ilmu dan kecerdasan tidak akan memberi jaminan terwujud masyarakat Pancasila.Dengan demikian dalam penyajian Pendidikan Kewarganegaraan itu, hendaknya guru dapat menggunakan aspek-aspek mata pelajaran yang lain. Yang mana mata pelajaran lain tersebut sebagai alat bantu dalam mendidik anak didiknya untuk membentuk suatu moral yang baik dan untuk mengarahkan anak didiknya agar dapat mewujudkan sesuatu prestasi belajar yang baik serta dapat memberi suatu pengarahan kedisiplinan terhadap anak didiknya. Oleh karena itu Pendidikan Kewarganegaraan merupakan suatu kesatuan pendidikan moral, dengan inti pokok pengetahuan tentang Pancasila sebagai pandangan hidup dan berdasarkan negara, maka penanaman pengetahuan itu bukan menjadi sasaran akhir, karena 
Didaktik : Jurnal IImiah PGSD STKIP Subang, ISSN Cetak : 2477-5673 ISSN Online : 2614-722X Volume V Nomor 2, Desember 2019

\begin{tabular}{lr}
\hline sasaran akhir dari & Pendidikan \\
Kewarganegaraan & adalah \\
menghayati dan & mengamalkan \\
Pancasila bersikap dan bertindak & menurut norma-norma Pancasila \\
serta berani mengamalkan
\end{tabular}

Pancasila.

Agar sasaran Pendidikan Kewarganegaraan yang demikian dapat dicapai apakah tugas guru PKn itu ? Seorang guru Pendidikan Kewarganegaraan dapat mendidik dan meneruskan pandangan hidup dan nilai-nilai yang dimiliki anak didiknya. Apabila tugas sebagai guru PKn sebagai yang dikemukakan tadi, maka bagaimana tugas guru PKn itu ? Bahwa disini seorang guru PKn harus dapat mendidik anak didiknya, yaitu meneruskan nilai-nilai Pancasila dengan contoh tauladan dalam hidupnya. Suatu contoh bagaimana menghormati orang lain, Cara mempergunakan waktu dengan baik, berdisiplin dan lain-lain.

Namun kalau kita melihat masalah-masalah yang sering terjadi dalam sekolah,sekolah,yang menyangkut tata tertib sekolah,umumnya prestasi belajar pendidikan Kewarganegaraan menurun, begitu juga sering timbul kedisiplinan siswa yang kurang, sehingga sangat mempengaruhi prestasi belajar Pendidikan Kewarganegaraan. Contoh, sering adanya siswa yang tidak mau mengikuti upacara, sering adanya kenakalan siswa dan lain-lain yang mana kesemuanya itu berpengaruh terhadap prestasi belajar Pendidikan Kewarganegaraan dan kedisiplinan siswa. Oleh sebab itu guru sangat mengharapkan adanya suatu hubungan antara ,kedisiplinan siswa dengan prestasi belajar dalam bidang Pendidikan kewarganegaraan supaya lebih ditingkatkan.

\section{B. Metode Penelitian}

Metode yang penulis gunakan dalam penelitian ini adalah metode penelitian lapangan (field research) dalam rangka mengetahui minat baca siswa yang ditopang dengan metode penelitian pustaka (library research) agar memiliki landasan teoretis yang kuat. Karenanya, alat pengumpulan data yang digunakan berupa angket, lembar observasi dan lembar pedoman wawancaraDalam penelitian ini penulis mengambil sampel secara acak (random sampling) dari kelas VIII SMP Negeri Satu Atap 1 Cipaku ,, diambil sebanyak 50 orang responden. 
Didaktik : Jurnal IImiah PGSD STKIP Subang, ISSN Cetak : 2477-5673 ISSN Online : 2614-722X Volume V Nomor 2, Desember 2019

Selain itu sumber data dalam penelitian ini adalah data wawancara dengan guru mata pelajaran

Pendidikan

Kewarganegaraan Kepala Sekolah dan bagian Tata Usaha. metode yang penulis gunakan dalam penelitian ini adalah metode penelitian lapangan (field research) dalam rangka mengetahui minat baca siswa yang ditopang dengan metode penelitian pustaka (library research) agar memiliki landasan teoretis yang kuat.

\section{Hasil Penelitian dan Pembahasan \\ 1. Kedisiplinan Siswa}

Data yang diperoleh dari disiplin belajar siswa $(\mathrm{X})$ berkisar 67 sampai 94. Skor tertinggi 94 dan terendah 67 dengan rentangan 27 . Secara keseluruhan skor yang diperoleh dari disiplin belajar siswa sebesar 3905 . Dari jumlah ini diperoleh mean 78.2, median 78.38 dan standar deviasi 5.75 (lampiran V).

Apabila data digambarkan dalam bentuk grafik histogram dan poligon, maka akan terlihat seperti gambar di bawah ini. Akan tetapi sebelumnya perlu dibuat tabel distribusi frekuensi dengan tambahan kolom titik tengah dan batas nyata. Untuk lebih jelasnya dapat dilihat pada tabel dan gambar berikut ini :

Tabel 1. Distribusi Frekuensi untuk keperluan pembuatan

Grafik Histogram dan Poligon tentang Disiplin Belajar Siswa.

\begin{tabular}{|c|c|c|}
\hline Kelas & Frekuensi & $\begin{array}{c}\text { Titik } \\
\text { tengah }\end{array}$ \\
\hline $67-71$ & 7 & 69 \\
\hline $72-76$ & 12 & 74 \\
\hline $77-81$ & 16 & 79 \\
\hline $82-86$ & 13 & 84 \\
\hline $87-91$ & 1 & 89 \\
\hline $92-96$ & 1 & 94 \\
\hline Jumlah & 50 & \\
\hline
\end{tabular}

2. Hasil Belajar Bidang Studi PKn

Data Yang diperoleh dari hasil belajar PKn (Y) berkisar 35 - 80. Skor tertinggi 80 dan terendah 35 dengan rentangan 45. Secara keseluruhan skor yang diperoleh dari hasil belajar PKn sebesar 3169. Dari jumlah ini diperoleh mean 64.1 modus 65.5 median 65.97 dan standar deviasi 10.35 (Lampiran VI). Apabila data tersebut digambarkan dalam bentuk grafik histogram dan poligon, maka akan terlihat seperti gambar di baawah ini. Terlebih dahulu dibuat tabel distribusi frekuensi.

Tabel 2. Distribusi frekuensi untuk keperluan pembuatan Grafik 
Didaktik : Jurnal IImiah PGSD STKIP Subang, ISSN Cetak : 2477-5673 ISSN Online : 2614-722X Volume V Nomor 2, Desember 2019

Histogram dan poligon tentang Hasil

Belajar PKn

\begin{tabular}{|c|c|c|}
\hline Kelas & Frekuensi & $\begin{array}{c}\text { Titik } \\
\text { tengah }\end{array}$ \\
\hline $35-42$ & 2 & 38.5 \\
\hline $43-50$ & 3 & 46.5 \\
\hline $51-58$ & 8 & 54.5 \\
\hline $59-66$ & 15 & 62.5 \\
\hline $67-74$ & 14 & 70.5 \\
\hline $75-82$ & 18 & 78.5 \\
\hline Jumlah & 50 & \\
\hline
\end{tabular}

Dari tabel gambar di atas terlihat bahwa frekuensi tertinggi terletak pada kelas interval 59 - 66 yaitu 15 diikuti dengan kelas interval $67-74$ yaitu 14. Frekuensi tersebut berada pada titik tengah 62.5 - 70.5. HI ini menunjukan bahwa skor disiplin belajar siswa sebagian besar responden berada pada kategori rata - rata. Hal tersebut ditunjukkan melalui tabel gambar di ataas karena sebagian besar jumlah responden (29 responden) berada diantara titik tengah 62.5 dan 70.5 .

a. Uji Normalitaas (Lilliefors)

Untuk mengetahui apakah data yang diperoleh berasal dari populasi berdistribusi normal atau tidak, maka dilakukan Uji Normalitas dengan menggunakan Uji Normalitas dari
Lilliefors.Kriteria pengujian pada Uji Lilliefors adalah $H_{0}$ diterima jika LOhitung kurang dari Lotabel. Populasi tersebut berdistribusi normal jika berhasil menerima $\mathrm{H}_{\circ}$

Data yang diperoleh dari variable $X$ dan variable $\hat{Y}$ berasal dari sampel dan populasi yang sama. Namun untuk mengetahui seberapa besar hasil perhitungannya, maka keduanya dilakukan perhitungan.

b. Variabel $X$

Dari hasil perhitungan diperoleh Lohitung sebesar 0.0873. Jika dikonsultasikan pada tabel Lilliefors dengan taraf signifikansi 0.05 dan $\mathrm{N}=$ 50 diperoleh Lotabel sebesar 0.125. Dengan demikian $\mathrm{H}_{0}$ diterima karena Lohitung kurang dari Lo tabel $(0.0873<$ 0.125). Hal ini berarti data pada variable $X$ berasal dari populasi yang berdistribusi normal (lampitan VII).

c. Variabel $Y$

Dari perhitungan diperoleh Lohitung sebesar 0.0706. Ini berarti lebih kecil dari Lotabel sebesar 0.125. Dengan demikian $\mathrm{H}_{\mathrm{o}}$ diterima karena Lohitung kurang dari Lotabel (0.0706 < 0.125 . Ini berarti data pada variable $\hat{Y}$ berasal dari populasi yang berdistribusi normal (lampiran VII). 
Didaktik : Jurnal Ilmiah PGSD STKIP Subang, ISSN Cetak : 2477-5673 ISSN Online : 2614-722X Volume V Nomor 2, Desember 2019

Untuk lebih jelasnya dapat dilihat pada tabel di bawah ini :

Tabel 3. Uji Normalitas Variabel X dan $Y$ dari 50 responden

\begin{tabular}{|l|l|l|l|l|l|}
\hline $\mathrm{N}$ & $\alpha$ & $\begin{array}{c}\text { varia } \\
\text { bel }\end{array}$ & $\begin{array}{c}\text { Lohitu } \\
\mathrm{ng}\end{array}$ & $\begin{array}{c}\text { LOta } \\
\text { bel }\end{array}$ & $\begin{array}{l}\text { Keputu } \\
\text { san }\end{array}$ \\
\hline 5 & 0.0 & $\mathrm{X}$ & 0.08 & 0.1 & $\mathrm{H}_{\mathrm{o}}$ \\
0 & 5 & $\hat{\mathrm{Y}}$ & 73 & 25 & diterim \\
5 & 0.0 & & 0.07 & 0.1 & $\mathrm{a}$ \\
0 & 5 & & 06 & 25 & $\begin{array}{l}\mathrm{H}_{\mathrm{o}} \\
\text { diterim } \\
\end{array}$ \\
\hline
\end{tabular}

d. Uji Linieritas.

Sebelum uji linieritas maka terlebih dahulu dicari persamaan regresi berbentuk $Y=a+b x$ dari hasil perhitungan diperoleh bentuk $\mathrm{Y}=$ $65.01+0.012 x$.

Adapun Hipotesis yang diajukan :

$\mathrm{H}_{\mathrm{o}} \quad=$ Regresi hipotesis, jika $\mathrm{Fh}<\mathrm{Ft}$

$\mathrm{H}_{\mathrm{i}} \quad=$ Regresi linier, jika

$\mathrm{Fh}>\mathrm{Ft}$

Dari perhitungan diperoleh $F_{\text {hitung }}$ sebesar 0.77. Jika dikonsultasikan pada $F_{\text {tabel }}$ dengan taraf signifikan 0.05 dan pada dk (18.30) diperoleh $F_{\text {tabel }}$ sebesar 1.93 dengan demikian hipotesis model linier diterima karena

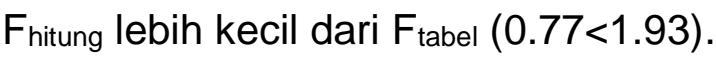

Ini berarti bahwa data tersebut mempunyai model linier (lampiran IX)

e. Uji Linieritas

\begin{tabular}{|c|c|c|c|c|c|}
\hline $\begin{array}{c}\text { U } \\
\text { ji }\end{array}$ & $\alpha$ & Dk & $F_{\text {hitu }}$ & $\begin{array}{c}F_{\text {tab }} \\
\text { el }\end{array}$ & $\begin{array}{c}\text { Keputus } \\
\text { an }\end{array}$ \\
\hline L & 0.0 & $(18.3$ & 0.7 & 1.9 & $\mathrm{H}_{0}$ \\
& 5 & $0)$ & 7 & 3 & diterima \\
\hline
\end{tabular}

3. Pengujian Hipotesis Penelitian dan Analisis Data

Dari data yang diperoleh, maka dilakukan analisis data yang bertujuan untuk mengetahui keberadaan data dalam pengujian hipotesis penelitian. Langkah yang ditempuh dalam analisis data ini yaitu menghubungkan dua jenis skor, skor disiplin belajar siswa dengan skor hasil belajar Pkn pada siswa SMP Negeri Satu Atap 1 Cipaku ,. Rumus untuk menghubungkan kedua skor tersebur adalah rumus Korelasi Product Moment. Dari perhitungan diperoleh $r_{x y}=0.006$ (lampiran X).

Untuk mengetahui ada tidaknya korelasi, maka koofisien korelasi yang dapat dikonsultasikan pada tabel angka kritik "r" product moment pada $\alpha=0.05$ dan $\mathrm{N}=50$ diperoleh rtabel sebesar 0.297. Dengan demikian rhitung lebih kecil dari rtabel $(0.006<0.297)$. Ini berarti tidak 
Didaktik : Jurnal Ilmiah PGSD STKIP Subang, ISSN Cetak : 2477-5673 ISSN Online : 2614-722X Volume V Nomor 2, Desember 2019

terdapat hubungan antara variable $\mathrm{x}$ dengan variable y.

4. Interprestasi Hasil Penelitian

Dari analisis data di atas dapat diketahui tidak terdapat hubungan antara disiplin belajar siswa dengan hasil belajar PKn sehingga dapat diinterprestasikan bahwa perubahan skor displin belajar siswa tidak mempengaruhi hasil belajar PKn.

Berdasarkan hasil penelitian ini, maka perlu dikaji lagi mengenai beberapa aspek yang berhubungan dengan system pembelajaran PKn. Ditolaknya hipotesis penelitian dapat saja karena adanya sistem pembelajaran yang salah, walaupun dari sisi kurikulum sangat jelas terlihat adanya keseluruhan aspek pada bidang studi PKn yang harus diajarkan, yaitu aspek Kognitif, afektif dan psikomotor. Dalam kenyataan sehari - hari, pembelajaran PKn juga tidak hanya mengajarkan aspek adektif dan psikomotor sesuai dengan yang tertera dalam GBPP. Yang menjadi persoalan berikutnya adalah, ternyata penilaian untuk bidang studi PKn masih terjebak dalam suatu rumus penilaian yang hanya mengindahkan aspek kognitif saja. Sedangkan aspek afektif dan psikomotor masih luput dari unsur penilaian pada akhir semester saat pembagian rapor. Nilai kognitif di antaranya dipengaruhi oleh kemampuan intelegensi dari disiplin belajar.

Berdasarkan hasil penelitian ini penulis merekomondasikan agar pihak terkait dan penetu kebijakan penilaian bidang studi PKn agar mengubah rumusan penilaian dan pengukuran hasil belajar siswa dalam bidang studi PKn. Karena sesungguhnya hakikat pembelajaran bidang studi PKn tidak hanya mengolah kecerdasan otak siswa saja dalam bentuk ranah kognitif, namun juga guru PKn bertanggung jawab mengembangkan aspek kecerdasan moral yang dicerminkan pada aspek afektif dan psikomotor dalam wujud sikap, perilaku dan disiplin belajar.

Rekomondasi dari penulis rasanya cukup beralasan untuk diperlihatkan agar pembelajaran PKn selama ini dan pada maasa yang akan dating tidak terjebak pada situasi yang kurang baik. Maksudnya di sini adalah agar pengukuran dan penilaian bidang studi PKn harus dapat mencerminkan pada setiap aspek yang ada. Yaitu kognitif, afektif dan psikomotor seperti yang penulis uraikan dalam kajian teori pada bab II. 
5. Diskusi

Kesimpulan hasil penelitian di atas menunjukkan bahwa hipotesis nol gagal ditolak artinya tidak terdapat hubungan antara disiplin belajar siswa dengan hasil belajar PKn SMP Negeri Satu Atap 1 Cipaku ,. Hal - hal yang mengakibatkan hipotesis penelitian tidak diterima menurut hemat penulis, banyak faktor yang mempengaruhi, diantaranya responden kurang serius dalam menjawab soal (angket) yang diberikan oleh peneliti, dan dapat juga responden tidak memahami maksud pernyataan yang terdapat dalam angket secara benar dan utuh, dan faktor kecerdasan dari masing masing responden.

\section{Kesimpulan}

Berdasarkan hasil penelitian dapat disimpulkan bahwa pengujian hipotesis yang dilakukan dengan rumus Korelasi Product Moment menghasilkan $r_{x y}$ sebesar 0.006 dan rtabel 0.297. $r_{x y}$ lebih kecil dari $r_{\text {tabel }}$ (0.006 $\leq 0.297)$, maka Ho diterima. Ini berarti tidak ada hubungan antara variable $X$ (Disiplin Belajar Siswa) dengan Variabel $Y$ (Hasil belajar PKn).

\section{DAFTAR PUSTAKA}

Djojonegoro,

Wardiman.(1998).Pembudayaan

Disiplin Nasioanal. Jakarta Depdikbud

Goble, Frank G. (1994). Mazhab Ketiga : Psikologi Humanistik Abraham Maslow .Yogyakarta : Penerbit Kanisius

Gordon, Thomas. (1996). Mengajar anak Berdisiplin Diri ; di rumah dan di sekolah. Jakarta : Gramedia.

Imran, Ali. (1993 ). Pembinaan Guru Indonesia. Jakarta : Pustaka Jaya

Kemendikbud. (1995). Kamus Besar Bahasa Indonesia. Jakarta : Balai Pustaka;

Pemda DKI Jakarta. (1995). Pedoman Pelaksanaan Gerakan Disip/n Nasional.Jakarta: Pemda DKI Jakarta

Purwanto, M Ngalim. (1998). Psikologi Pendidikan. Cetakan Ketiga Bandung PT Remaja Rosdakarya

Santoso, Dwi. (1994). Pendidikan Pancasila dan Kewarganegaraan 
SLTP Kelas 2.Jakarta:

Depdikbud

Silalahi. Bennet. (1998). Performance

Appraisal. Jakarta STIM-LPMI,

SLTP Negeri 171. Tata Tertib

Sekolah

Soevirjanto. (1994). Pendidikan

Pancasila dan

Kewarganegaraan. Jakarta :

Aries Lima, hlm V,

Sumadi, Tjipto, dan M. Japar. (1999).

Pengajaran IImu Pengetahuan

Sosial. Jakarta : Departemen

Pendidikan dan Kebudayaan

Dirjen Dikdasmen Bagian Proyek

Penataran Guru SLTP Setara D-

III.

Syah, Muhibbin. (1997). Psikologi

Pendidikan dengan Pendekatan

Baru. Bandung : PT Remaja

Rosdakarya. 